\title{
Highly Porous Titanium Cups versus Hydroxyapatite-Coated Sockets: Midterm Results in Metachronous Bilateral Total Hip Arthroplasty
}

\author{
Francesco Castagnini $^{\mathrm{a}}$ Barbara Bordini ${ }^{\mathrm{b}}$ Makiko Yorifuji ${ }^{\mathrm{b}, \mathrm{c}}$ Federico Giardina ${ }^{\mathrm{a}}$ \\ Simone Natali ${ }^{a}$ Francesco Pardo ${ }^{a}$ Francesco Traina ${ }^{a}$ \\ ${ }^{a}$ Ortopedia-Traumatologia e Chirurgia Protesica e dei Reimpianti d'Anca e di Ginocchio, IRCCS Istituto Ortopedico

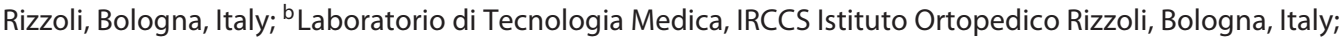 \\ 'Department of Orthopedic Surgery, Tokyo Medical University, Tokyo, Japan
}

\section{Highlights}

- Newly developed cups did not always prove better. In this paper the clinical and radiographic midterm outcomes of highly porous titanium cups and conventional hydroxyapatite-coated sockets in the same patient were compared, controlling the inter-individual biological factors affecting osseointegration. The outcomes showed that highly porous titanium cups were not inferior to conventional sockets and provided a valid bony ingrowth.

\section{Keywords}

Ti-Por · Additive manufacturing · Electron beam melting · Pore $\cdot$ Highly porous titanium cups

\footnotetext{
Abstract

Objective: Highly porous titanium cups have been recently introduced, with contradictory outcomes. A retrospective consecutive case series involving bilateral metachronous total hip arthroplasties (THA) performed with 2 different cups, i.e., Fixa (F) and Fixa Ti-Por (T) (Adler Ortho, Milan, Italy), and the same stem, was evaluated. T sockets, manufactured using electron beam melting, were supposed to prove superior in terms of clinical results, survival rates, and radiographic parameters in comparison to hydroxyapatite-coated F cups with conventional porosity. Subjects and Methods: Twentyfour bilateral metachronous THAs with an F cup on one side and a T socket on the other side were evaluated. Preoperative and postoperative Harris hip scores (HHS) were collect-
}

ed for every patient. Radiographic signs of loosening were assessed. The radiographic signs of osseointegration (radiolucent lines, superolateral buttress, inferomedial buttress, radial trabeculae, and stress shielding) were evaluated. $\boldsymbol{R} \boldsymbol{e}$ sults: No intraoperative complications occurred. The mean HHS score was excellent and comparable in both groups. At the mean follow-up of 134 months $(F)$ and 79 months $(T)$, no cup or liner revisions were performed. No radiographic signs of loosening were reported. All of the patients revealed 3 parameters of good bony ingrowth at least. Both groups showed similar radiographic parameters regarding osseointegration, which were stable over the time. Stress shielding was more evident in the T cohort $(p=0.07)$. Conclusion: Highly porous titanium cups produced using an additive manufacturing and electron beam melting technology achieved reliable midterm clinical and radiographic results not inferior to those of second-generation cups.

(c) 2019 The Author(s)

Published by S. Karger AG, Basel

\begin{tabular}{|c|c|c|}
\hline KARGER & $\begin{array}{l}\text { (c) } 2019 \text { The Author(s) } \\
\text { Published by S. Karger AG, Basel }\end{array}$ & $\begin{array}{l}\text { Karger } \\
\text { Open access }\end{array}$ \\
\hline $\begin{array}{l}\text { E-Mail k } \\
\text { www.ka }\end{array}$ & $\begin{array}{l}\text { This is an Open Access article licensed } \\
\text { Attribution-NonCommercial- } 4.0 \text { Inte } \\
\text { (http://www.karger.com/Services/Ope } \\
\text { the online version of the article only. } L \\
\text { mercial purposes requires written per }\end{array}$ & $\begin{array}{l}\text { the Creative Commons } \\
\text { al License (CC BY-NC) } \\
\text { sLicense), applicable to } \\
\text { d distribution for com- }\end{array}$ \\
\hline
\end{tabular}

Francesco Castagnini, MD

Ortopedia-Traumatologia e Chirurgia Protesica e dei Reimpianti d'Anca e di Ginocchio IRCCS Istituto Ortopedico Rizzoli, Via Pupilli 1

IT-40136 Bologna (Italy)

E-Mail francescocastagnini@hotmail.it 


\section{Introduction}

A third generation of cementless cups has been recently introduced in order to improve the initial "scratch fit" of the sockets and the bony ingrowth, mostly acting on highly porous surfaces and mechanical properties [1-9]. The main features were: a high porosity $(>60 \%)$, a large pore size $(>200 \mu \mathrm{m})$, diffuse pore interconnections, a low elastic modulus (0.01-30 GPa), and a high coefficient of friction (i.e., 1) [1, 2, 7-9]. The high porosity was reported to improve the local vascularization (in terms of the number and size of vessels), stimulating a better bony ingrowth and reducing the fibrotic peri-implant tissue [4-6]. Tantalum cups were the first acetabular components with such peculiarities to be released; reliable long-term results were achieved in primary and revision total hip arthroplasties (THA) [3]. Titanium and titanium alloy cups with highly porous surfaces were later developed, with short- and midterm successful outcomes [1, 2, 7-9]. However, despite the low revision rates, some concerns about osseointegration and radiolucency arose [7-9]. Thus, more investigations about these new titanium cups are still required, in particular comparative assessments with the conventional secondgeneration sockets. The aim of this study was to compare the clinical and radiological outcomes of 2 different cementless modular cups manufactured from a titanium alloy, at a midterm follow-up, i.e., a second generation socket versus a third generation component, implanted with the same stem in the same patient (bilateral metachronous THAs). We hypothesized that, in 2 homogenous groups with no inter-individual biological variations, the highly porous titanium cup would prove superior, or at least not inferior, in terms of clinical and radiological assessments.

\section{Subjects and Methods}

The hospital database was searched for bilateral ceramic-onceramic THA with a Fixa (Adler Ortho, Milan, Italy) cup (F) on one side and Fixa Ti-Por (Adler Ortho) cup (T) on the other side, implanted since 2005. Two hundred twelve cases were detected.

In order to achieve 2 homogenous groups allowing a fully reliable comparison between $\mathrm{F}$ and $\mathrm{T}$ sockets, the following inclusion criteria were required: primary cementless implants with ceramicon-ceramic coupling and the same stem (Apta; Adler Ortho) implanted with a uniform surgical approach (lateral).

A minimum follow-up of 3 years and adherence to pre-established clinical and radiographic follow-ups (1, 6, and 12 months and then biennially) was also required. High-grade dysplastic patients (grades 3 and 4 according to Crowe classification) and those with congenital pathologies and severe acetabular deformities were not admitted [10].
A retrospective, consecutive case series of 24 prospectively followed patients (17 females [70.8\%] and 7 males [29.2\%]) was eventually considered eligible for this study (Table 1).

Cup Features, Implants, and Surgical Techniques

The F cup was a Ti6Al4V hemispherical socket presenting a pure titanium bead-sintered porous coating with plasma sprayed hydroxyapatite. The nominal bead diameter was $0.3 \mathrm{~mm}$. Cups from 42 to $46 \mathrm{~mm}$ had 2 layers of sinterized beads, whereas another bead coating was added for larger cups; thus the thickness of the first 4 sockets was $0.7 \mathrm{~mm}$, increasing to $1.05 \mathrm{~mm}$ from the 48 $\mathrm{mm}$ diameter cups. The hydroxyapatite coating was $70 \pm 20 \mu \mathrm{m}$ thick. The mean porosity was $30 \%$.

The T cup was released in 2007 as an evolution of the previous F socket. The hemispherical Ti6Al4V cup is produced using additive manufacturing, in particular electron beam melting technology [2]. This technique allows melting of thin layers of metal powder, modeling a bulk construct which respects the original metal alloy properties and integrates a fine trabecular surface. The external surface is characterized by multiple $0.4-\mathrm{mm}$ spikes with a mean porosity of $65 \%$ and $700-\mu \mathrm{m}$ holes.

Six experienced surgeons with more than 50 THAs per year were involved. All of the procedures were performed using a lateral approach with gluteal muscle detachment and reinsertion. The acetabulum was under-reamed according to the manufacturer's protocol; the $\mathrm{F}$ cup required a $1-\mathrm{mm}$ under-reaming whereas the T cup was $2 \mathrm{~mm}$ larger than the corresponding reamer. Screw fixation was added only in 1 case (F group). Cup positioning aimed to achieve $40-45^{\circ}$ of abduction and $10-15^{\circ}$ of anteversion [7]. The ceramic liner was manually inserted and hammered when proper seating was achieved. Third-generation ceramic couplings (Biolox Forte; Ceramtec, Plochingen Germany) were used in 16 cases (66.7\%) in the F group and in 1 case in the $\mathrm{T}$ cohort (4.2\%). Fourth-generation ceramic bearing surfaces (Biolox Delta; Ceramtec) were positioned in 8 cases $(33.3 \%)$ in the F group and in 23 cases (95.8\%) in the T group. The same rehabilitation protocol was used for both of the groups, regardless the level of activity or age.

\section{Clinical Evaluation}

Clinical evaluation was performed using the Harris hip score (HHS) in the preoperative setting and at the last available followup [10]. Implant survival was assessed as well using the KaplanMeier curve; the endpoint was cup or liner revision.

\section{Radiographic Assessment}

Plain pelvis X-rays were evaluated at every pre-established follow-up (1, 6, and 12 months and biennially). The measurements were manually performed by one operator (blind to the clinical outcomes and not involved in the surgical procedures), after proper calibration, using Carestream Vue Pacs (Rochester, NY, USA).

Cup abduction, cup anteversion (Lewinnek's method), and height and medialization of the center of rotation were assessed in the first postoperative X-ray (1 month, baseline radiograph) and used as a reference (Table 1). The measurement techniques were detailed in previous papers $[10,11]$.

Loosening occurred when the cup migrated more than $3 \mathrm{~mm}$ or was inclined more than $5^{\circ}$ in comparison to the baseline radiographs or when the acetabular component was bordered by a progressive radiolucent line greater than $2 \mathrm{~mm}$ [11]. 
Table 1. Demographic values and cup positioning parameters

\begin{tabular}{|c|c|c|c|c|c|}
\hline \multirow[t]{2}{*}{ Variable } & \multicolumn{2}{|c|}{ Mean \pm SD or $n(\%)$} & \multicolumn{2}{|c|}{ Median (range) } & \multirow[t]{2}{*}{$p$ value } \\
\hline & Fixa & Fixa Ti-Por & Fixa & Fixa Ti-Por & \\
\hline Age at THA & $58.2 \pm 11.2$ & $62.7 \pm 11.0$ & $58.5(35-78)$ & $62.5(43-82)$ & 0.248 \\
\hline BMI & $25.2 \pm 3.8$ & $25.1 \pm 3.7$ & $25(20-31)$ & $24.5(20-31)$ & 0.488 \\
\hline Diagnosis & & & & & 0.429 \\
\hline Osteoarthritis & $19(79.2)$ & $21(87.5)$ & & & \\
\hline Avascular necrosis & $1(4.1)$ & - & & & \\
\hline Fracture & - & $1(4.2)$ & & & \\
\hline Dysplasia & $4(16.7)$ & $2(8.3)$ & & & \\
\hline Side & & & & & 0.387 \\
\hline Left & $14(58.3)$ & $10(41.7)$ & & & \\
\hline Right & $10(41.7)$ & $14(58.3)$ & & & \\
\hline Cup abduction, degrees & $42.8 \pm 8.2$ & $40.6 \pm 11.6$ & $43.0(27-59)$ & $44.5(9-59)$ & 0.772 \\
\hline Cup anteversion, degrees & $14.6 \pm 6.2$ & $15.6 \pm 6.4$ & $13.5(4-28)$ & $15.0(6-34)$ & 0.770 \\
\hline Center of rotation height, $\mathrm{mm}$ & $19.5 \pm 4.9$ & $20.0 \pm 4.9$ & $19.5(12-30)$ & $19.0(13-31)$ & 1.000 \\
\hline Center of rotation medialization, $\mathrm{mm}$ & $30.6 \pm 6.4$ & $30.4 \pm 6.5$ & $31.0(16-40)$ & $32.0(18-40)$ & 0.770 \\
\hline
\end{tabular}

No significant differences were evident between the 2 cohorts.
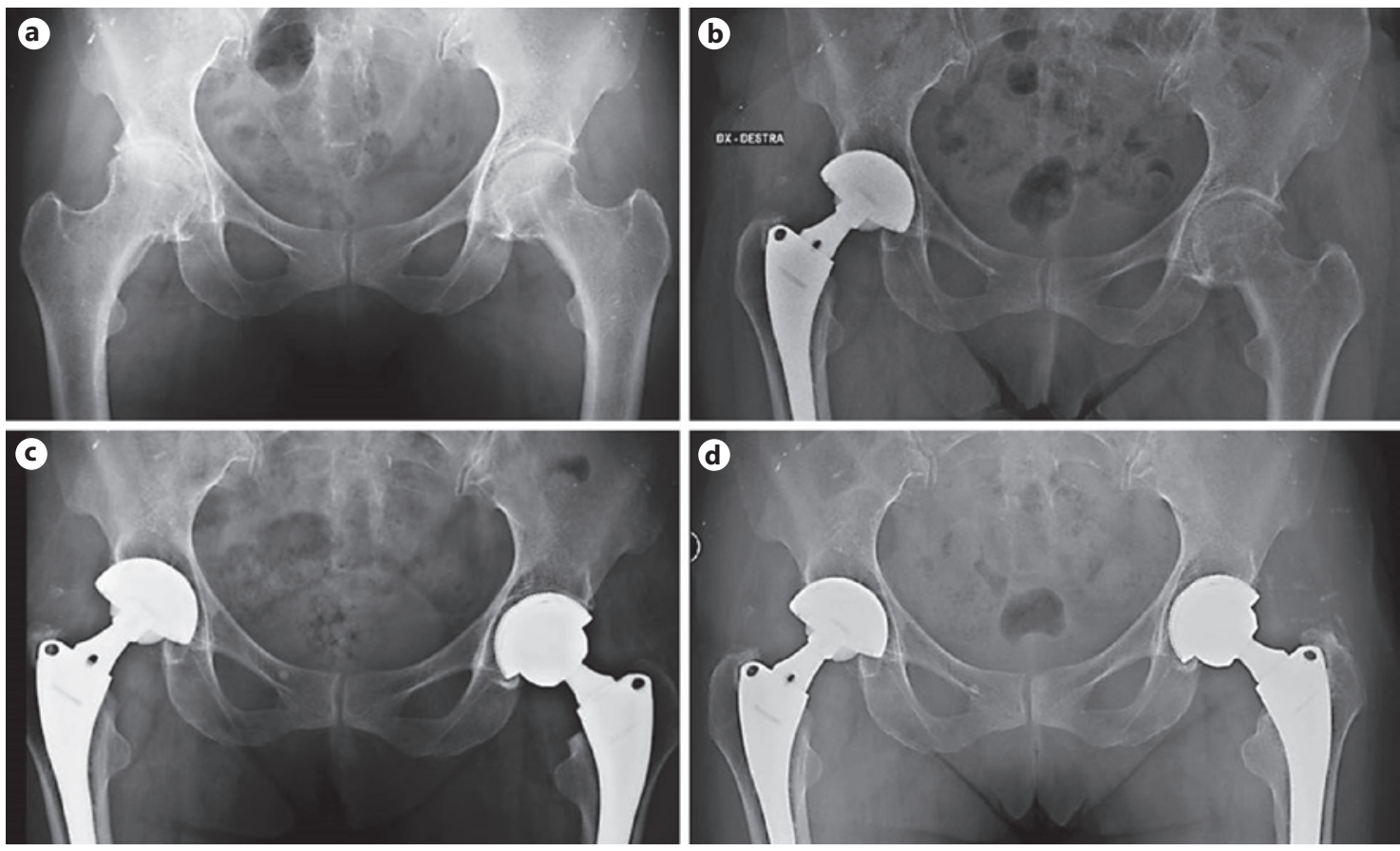

Fig. 1. A 53-year-old female affected with hip osteoarthritis underwent a bilateral metachronous THA (T on the left and $\mathrm{F}$ on the right) (a, b). The T cup showed a persistent gap in zone B after 1 year (c). At the last follow-up, the gap disappeared and a good bony ingrowth with radial trabeculae was evident (d).

Gaps, i.e., areas with no initial bone-cup contact in the baseline $\mathrm{X}$-rays, were evaluated [11]. Gaps were differentiated from radiolucent lines, occurring later and not present in the baseline X-rays [11]. Cup osseointegration was evaluated in the radiographs performed after 1 year. Variations in the following X-rays were re- ported. The criteria described by Moore et al. [12] were adopted. Radiolucency location according to DeLee and Charnley zones was provided [12]. Stress shielding was graded according to Engh et al. [13] (mild, moderate, or severe). Stem integration was also assessed $[10,13]$. 

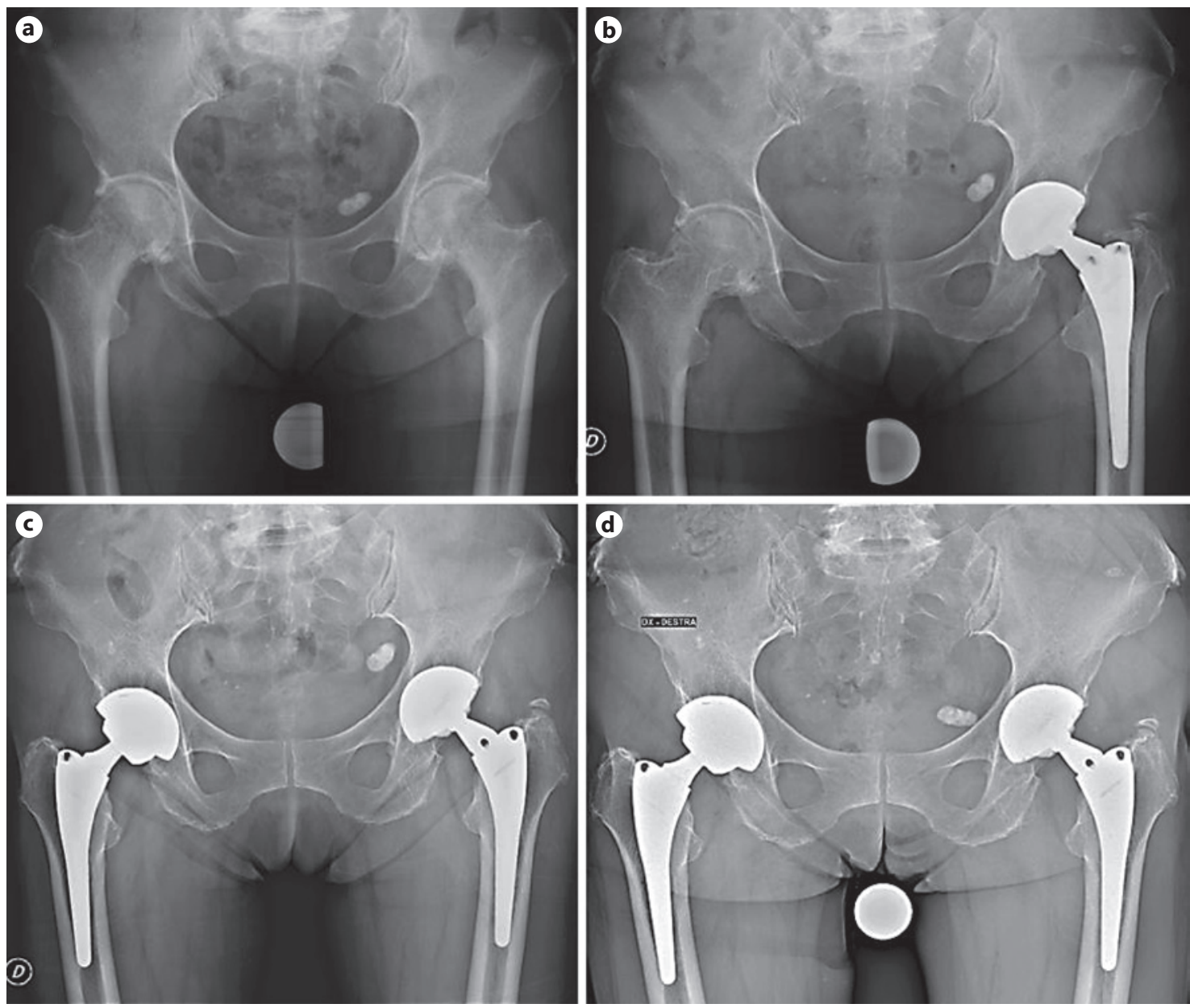

Fig. 2. A 71-year-old female affected with osteoarthritis underwent a bilateral metachronous THA (F on the left and $\mathrm{T}$ on the right) $(\mathbf{a}-\mathbf{c})$. A dependable, stable bony ingrowth was evident on both sides at the last follow-up (c, d), with more evident stress shielding around the T socket.

Statistical Analysis

Quantitative data were reported as means \pm SD or medians (range). Differences between the 2 groups were assessed using the Mann-Whitney $U$ test for nonparametric data for the continuous and discrete variables. The $\chi^{2}$ test or Fisher's exact test was adopted for categorical variables (osseointegration parameters). SPSS software (version 14.0.1; Chicago, IL, USA) was used for the statistical analyses. $p<0.05$ was considered statistically significant.

\section{Results}

Both groups were homogenous in terms of demographic variables and positional parameters (Table 1).

No intraoperative complications were reported. The mean follow-up for F cups was $134 \pm 13.1$ months (range: 108-156 months) and for T cups it was $79 \pm 30.2$ months (range: $36-132$ months). F cups started from a preoperative HHS score of $45.7 \pm 10.1$ points (range: $31.5-56.1$ ) and achieved a final value of $93.3 \pm 4.8$ points (range: 86.3-99.6) $(p<0.05)$. The preoperative HHS score for T cups was $46.5 \pm 9.3$ points (range: $30.3-56.9$ ), whereas the postoperative HHS score was $94.2 \pm 4.1$ points (range: 89.3-99.7). One patient in the F group reported a squeaking noise after 3 years. In the T group, 2 periprosthetic femoral fractures occurred after 2 and 3 years; 1 case was treated with open reduction and osteosynthesis, while stem revision was required for the other patient.

No cup or liner revision was performed in either group. No radiographic loosening occurred at the final follow-up.

Two patients ( 1 for each group) had incomplete gap filling after the first year. The gaps were located in zone $\mathrm{B}$ 
( $\mathrm{T}$ patient) and in zone $\mathrm{C}$ (F patient). The gap in the $\mathrm{T}$ patient disappeared at the final follow-up (Fig. 1)

All of the patients had 3 radiographic signs of osseointegration at the last follow-up (Fig. 2). No significant differences regarding osseointegration parameters were evident between the 2 groups (Table 2). No variations were evident at the subsequent follow-ups (Fig. 2)

\section{Discussion}

Some authors have reported noteworthy clinical and survival outcomes of third-generation titanium sockets [2, 14-18]. On the other side, a few authors have been more cautious: some new titanium cups have been associated with high rates of radiolucent lines and aseptic loosening $[7,9,19,20]$ (Table 3 ).

In order to compare the clinical and radiological outcomes of 2 different generations of sockets, a consecutive case series of bilateral non-simultaneous THAs was evaluated. The-second generation F cup, implanted with ceramic-on-ceramic bearing surfaces and Apta stems, was compared to the third-generation $\mathrm{T}$ component, implanted with ceramic-on-ceramic couplings and the same stem on the contralateral side. Such a study design strongly reduced the effects of confounding factors, in particular different bearing surfaces, different stems, and different biological influences related to the patient himself or herself. The groups were homogenous in terms of demographic data and cup positioning parameters.

Both cups achieved excellent clinical results and survival rates. No cup loosening was reported at the midterm follow-up. The radiographic signs of osseointegration were analogous in both groups, with every socket demonstrating at least 3 parameters related to strong bony fixation [12]. Stress shielding showed a slight, non-significantly different distribution: $\mathrm{T}$ sockets were correlated with higher percentages of bone rarefaction in zone B. The different designs and surfaces of these 2 sockets may have influenced the bone deformation around the implant [21]. In particular, the thicker but more elastic and porous $\mathrm{T}$ cup may have shielded the $\mathrm{B}$ zone, describing a different adaptive bone remodeling around the cup. However, such an explanation is merely presumptive and should be better defined with a bone mineral density analysis.

The good midterm outcomes provided by the present study seemed to confirm the previous findings about third-generation sockets produced using additive manufacturing, specifically electron beam melting (Table 3 ).
Table 2. Stress shielding distribution

\begin{tabular}{|c|c|c|c|}
\hline Variable & Fixa & Fixa Ti-Por & $p$ value \\
\hline Radiolucency & & & 1.000 \\
\hline Present & $0(0)$ & $0(0)$ & \\
\hline Absent & $24(100)$ & $24(100)$ & \\
\hline $\begin{array}{l}\text { Radiolucency location } \\
\text { (DeLee-Charnley) }\end{array}$ & & & l \\
\hline A & $1(4.2)$ & - & \\
\hline $\mathrm{B}$ & - & $1(4.2)$ & \\
\hline $\mathrm{B}-\mathrm{C}$ & - & $1(4.2)$ & \\
\hline $\mathrm{C}$ & $1(4.2)$ & - & \\
\hline \multicolumn{4}{|l|}{ Superolateral buttresses } \\
\hline Present & $24(100.0)$ & $23(95.8)$ & 1.000 \\
\hline Absent & - & $1(4.2)$ & \\
\hline Radial trabeculae & & & 1.000 \\
\hline Present & $23(95.8)$ & $23(95.8)$ & \\
\hline Absent & $1(4.2)$ & $1(4.2)$ & \\
\hline \multicolumn{4}{|l|}{ Inferomedial buttresses } \\
\hline Present & $20(83.3)$ & $21(87.5)$ & 1.000 \\
\hline Absent & $4(16.7)$ & $3(12.5)$ & \\
\hline Stress shielding (zone B) & & & 0.067 \\
\hline Absent & $10(41.7)$ & $4(16.7)$ & \\
\hline Mild & $12(50.0)$ & $19(79.1)$ & \\
\hline Moderate & $2(8.3)$ & - & \\
\hline Severe & - & $1(4.2)$ & \\
\hline
\end{tabular}

Values are presented as numbers (\%). The stress shielding distribution showed a nonsignificant trend: bone rarefaction in zone B was more frequent in T cups.

It should be clearly stated that, in the case of highly porous sockets, every cup fabrication has to be individually evaluated, as mechanical properties and porosity are manufacturing dependent. Thus, the promising results of the cups produced using additive manufacturing and electron beam melting should not be extended to all third-generation titanium cups, as Tritanium (Stryker; Mahwah, NJ, USA) cups have shown [7, 9].

To the best of our knowledge, the present study is the first to describe the outcomes of 2 different generations of sockets implanted with the same stem in the same patient. Moreover, this study deals with one of the newest highly porous titanium cups, which is scarcely documented in the literature. The main advantages of this study are related to the maximum control of every possible confounding factor, including inter-individual variations in acetabular bone quality and bony ingrowth. The limitations of this study are mainly due to its retrospective design, the midterm follow-up of the T cup, the small number of patients, the measurement techniques (manual procedure; single, blind author) and the lack of qualitative and quan- 
Table 3. Clinical studies on EBM cups in primary THA

\begin{tabular}{|c|c|c|c|c|c|c|c|c|c|}
\hline Study & $\begin{array}{l}\text { Year of } \\
\text { publica- } \\
\text { tion }\end{array}$ & Type of study & $\begin{array}{l}\text { THAs involved, } \\
n\end{array}$ & $\begin{array}{l}\text { Mean age of the } \\
\text { patients, years }\end{array}$ & Cup type & $\begin{array}{l}\text { Mean follow- } \\
\text { up, years }\end{array}$ & Clinical results & $\begin{array}{l}\text { Survival rate, } \\
\%\end{array}$ & Notes \\
\hline $\begin{array}{l}\text { Perticarini } \\
\text { et al. [17] }\end{array}$ & 2015 & $\begin{array}{l}\text { Prospective case series } \\
\text { (clinical) }\end{array}$ & 134 & 57.5 & $\begin{array}{l}\text { Delta TT } \\
\text { Lima }\end{array}$ & 6.1 & HHS: 95.9 & 99.3 (cups) & \\
\hline $\begin{array}{l}\text { Massari et al. } \\
{[18]}\end{array}$ & 2017 & $\begin{array}{l}\text { Multicenter, } \\
\text { prospective } \\
\text { case series } \\
\text { (clinical and DEXA) }\end{array}$ & 91 & 67 & $\begin{array}{l}\text { Delta TT } \\
\text { Lima }\end{array}$ & Minimum: 2 & HHS: 99 & 100 (cups) & $\begin{array}{l}\text { Good periacetabular bone } \\
\text { mass density }\end{array}$ \\
\hline $\begin{array}{l}\text { Imai et al. } \\
{[19]}\end{array}$ & 2019 & $\begin{array}{l}\text { Retrospective, } \\
\text { case control, } \\
\text { on dysplastic hips }\end{array}$ & $\begin{array}{l}136 \\
(101 \mathrm{EBM}, \\
35 \mathrm{HA})\end{array}$ & $\begin{array}{l}62.5(\mathrm{EBM}) \\
\text { vs. } 64.5(\mathrm{HA})\end{array}$ & $\begin{array}{l}\text { SQRUM TT } \\
\text { Kyocera vs. } \\
\text { SQRUM HA } \\
\text { Kyocera }\end{array}$ & $\begin{array}{l}2.1(\mathrm{EBM}) \mathrm{vs} . \\
2.2 \\
(\mathrm{HA})\end{array}$ & $\begin{array}{l}\text { JOA: } 88.2 \\
\text { (EBM) vs. } \\
87 \text { (HA) }\end{array}$ & 100 in both groups & $\begin{array}{l}\text { Apparent better osseointe- } \\
\text { gration in HA group }\end{array}$ \\
\hline $\begin{array}{l}\text { Australian Ortho- } \\
\text { pedic Association } \\
\text { National Joint } \\
\text { Replacement } \\
\text { Registry [20] }\end{array}$ & 2017 & Registry study & 95 & NA & $\begin{array}{l}\text { Delta TT } \\
\text { Lima }\end{array}$ & 3 & NA & $\begin{array}{l}93.7 \text { at } \\
3 \text { years }\end{array}$ & $\begin{array}{l}\text { Main reason for revision: } \\
\text { loosening }\end{array}$ \\
\hline $\begin{array}{l}\text { Castagnini } \\
\text { et al. [2] }\end{array}$ & 2018 & $\begin{array}{l}\text { Registry study } \\
\text { (EBM vs. all ce- } \\
\text { mentless cups) }\end{array}$ & $\begin{array}{l}9,864 \text { (EBM) vs. } \\
26,923 \\
\text { (all) }\end{array}$ & $\begin{array}{l}68(\mathrm{EBM}) \\
\text { vs. } 69 \text { (all) }\end{array}$ & $\begin{array}{l}\text { Ti-Por } \\
\text { Adler vs. } \\
\text { all }\end{array}$ & $\begin{array}{l}3.2(\mathrm{EBM}) \text { vs. } \\
4.1 \\
\text { (all) }\end{array}$ & NA & $\begin{array}{l}98.7(\mathrm{EBM}) \\
\text { vs. } 97.9 \text { (all) }\end{array}$ & $\begin{array}{l}\text { EBM cups not inferior to } \\
\text { any of the cementless cups, } \\
\text { regardless of the bearings }\end{array}$ \\
\hline
\end{tabular}

titative periacetabular bone assessments. Modular necks should not be regarded as an important weak point, as the titanium-on-titanium coupling makes the Apta stem a low-risk implant in terms of failure and metallosis [10]. prospective case control studies with longer follow-ups and, possibly, with bone mineral density analyses are required to outline the dependability of such sockets.

\section{Statement of Ethics}

The subjects gave their informed written consent. The study protocol was approved by the local institutional review board.

\section{Disclosure Statement}

The authors declare no conflict of interests.

\section{References}

1 Callaghan JJ, Rosenberg AG, Rubash HE, Clohisy JC, Beaulè PE, Della Valle CJ. The adult hip. 3rd ed. Philadelphia, PA, US: Wolters Kluwer; 2016.

2 Castagnini F, Bordini B, Stea S, Calderoni PP, Masetti C, Busanelli L. Highly porous titanium cup in cementless total hip arthroplasty: registry results at eight years. Int Orthop. 2018 Aug; https://doi.org/10.1007/s00264-018-4102-9.

3 Banerjee S, Issa K, Kapadia BH, Pivec R, Khanuja HS, Mont MA. Highly-porous metal option for primary cementless acetabular fixation. What is the evidence? Hip Int. 2013 Nov-Dec;23(6):509-21.

4 Ponader S, von Wilmowsky C, Widenmayer M, Lutz R, Heinl P, Körner C, et al. In vivo performance of selective electron beam-melted Ti-6Al-4V structures. J Biomed Mater Res A. 2010 Jan;92(1):56-62.
5 Otsuki B, Takemoto M, Fujibayashi S, Neo M, Kokubo T, Nakamura T. Pore throat size and connectivity determine bone and tissue ingrowth into porous implants: three-dimensional micro-CT based structural analyses of porous bioactive titanium implants. Biomaterials. 2006 Dec;27(35): 5892-900.

6 Taniguchi N, Fujibayashi S, Takemoto M, Sasaki K, Otsuki B, Nakamura T, et al. Effect of pore size on bone ingrowth into porous titanium implants fabricated by additive manufacturing: an in vivo experiment. Mater Sci Eng C. 2016 Feb;59:690-701.

7 Carli AV, Warth LC, de Mesy Bentley KL, Nestor BJ. Short to Midterm Follow-Up of the Tritanium Primary Acetabular Component: A Cause for Concern. J Arthroplasty. 2017 Feb;32(2):463-9.
8 Yoshioka S, Nakano S, Kinoshita Y, Nakamura M, Goto T, Hamada D, et al. Comparison of a highly porous titanium cup (Tritanium) and a conventional hydroxyapatitecoated porous titanium cup: A retrospective analysis of clinical and radiological outcomes in hip arthroplasty among Japanese patients. J Orthop Sci. 2018 Nov;23(6):96772 .

9 Long WJ, Nayyar S, Chen KK, Novikov D, Davidovitch RI, Vigdorchik JM. Early aseptic loosening of the Tritanium primary acetabular component with screw fixation. Arthroplast Today. 2018 Jan;4(2):169-74.

10 Montalti M, Castagnini F, Giardina F, Tassinari E, Biondi F, Toni A. Cementless Total Hip Arthroplasty in Crowe III and IV Dysplasia: High Hip Center and Modular Necks. J Arthroplasty. 2018 Jun;33(6):1813-9. 
11 Wegrzyn J, Kaufman KR, Hanssen AD, Lewallen DG. Performance of Porous Tantalum vs. Titanium Cup in Total Hip Arthroplasty: Randomized Trial with Minimum 10Year Follow-Up. J Arthroplasty. 2015 Jun; 30(6):1008-13.

12 Moore MS, McAuley JP, Young AM, Engh CA Sr. Radiographic signs of osseointegration in porous-coated acetabular components. Clin Orthop Relat Res. 2006 Mar;444(444): 176-83.

13 Engh CA Jr, McAuley JP, Sychterz CJ, Sacco ME, Engh CA Sr. The accuracy and reproducibility of radiographic assessment of stressshielding. A postmortem analysis. J Bone Joint Surg Am. 2000 Oct;82-A(10):1414-20.

14 Sillesen NH, Greene ME, Nebergall AK, Nielsen PT, Laursen MB, Troelsen A, et al. Three year RSA evaluation of vitamin E diffused highly cross-linked polyethylene liners and cup stability. J Arthroplasty. 2015 Jul;30(7):1260-4.
15 Naziri Q, Issa K, Pivec R, Harwin SF, Delanois RE, Mont MA. Excellent results of primary THA using a highly porous titanium cup. Orthopedics. 2013 Apr;36(4):e390-4.

16 Naudie DD, Somerville L, Korczak A, Yuan X, McCalden RW, Holdsworth D, et al. A randomized trial comparing acetabular component fixation of two porous ingrowth surfaces using RSA. J Arthroplasty. 2013 Sep;28(8 Sup$\mathrm{pl):48-52.}$

17 Perticarini L, Zanon G, Rossi SM, Benazzo FM. Clinical and radiographic outcomes of a trabecular titanium ${ }^{\mathrm{TM}}$ acetabular component in hip arthroplasty: results at minimum 5 years follow-up. BMC Musculoskelet Disord. 2015 Dec;16(1):375.

18 Massari L, Bistolfi A, Grillo PP, Borré A, Gigliofiorito G, Pari C, et al. Periacetabular bone densitometry after total hip arthroplasty with highly porous titanium cups: a 2-year followup prospective study. Hip Int. 2017 Nov; 27(6):551-7.
19 Imai H, Miyawaki J, Kamada T, Maruishi A, Takeba J, Miura H. Radiolucency around highly porous sockets and hydroxyapatitecoated porous sockets in total hip arthroplasty for hip dysplasia. Eur J Orthop Surg Traumatol. 2019 Apr;29(3):611-8.

20 Australian Orthopaedic Association National Joint Replacement Registry [Internet]. Annual reports 2017 [cited 2018 Sep 22]. https:// aoanjrr.sahmri.com/annual-reports-2017/ prostheses-investigations/-/document_library_display/kRS 13 g g c K G 3 N/ view/397922.

21 Ghosh R, Gupta S. Bone remodelling around cementless composite acetabular components: the effects of implant geometry and implant-bone interfacial conditions. J Mech Behav Biomed Mater. 2014 Apr;32:257-69. 